\title{
Visualizing Socio-techno-natural Processes: Issues and Challenges
}

\author{
E.A. Dergacheva ${ }^{1}$ \\ eadergacheva2013@yandex.ru \\ ${ }^{1}$ Bryansk State Technical University, Bryansk, Russia
}

\begin{abstract}
Contemporary models and systems of data visualization, implemented on the basis of information technology, individually cover social, technological and natural processes of the world development. Modern world is developing in the conditions of transformational transitional processes, when the artificial shell, the technosphere, created by the society becomes the leading life-support system instead of the biosphere. It is a full-fledged participant in the exchange processes between a globalizing technogenic society and transforming nature, which allows us to talk about forming socio-techno-natural laws of developing the world and life. There are no integrative visual models in the world that represent evolutionary changes in three systems simultaneously - society (and man), the technosphere and the technologically transformed biosphere, on the basis of which it is possible to predict the formation of a sustainable future for humanity in connection with the expansion of socio-technonatural processes. The generally recognized visualization methodology must be supplemented by the methodology of the philosophy of the world socio-technogenic development and the change in the evolution of life for a better visual representation and explanation of the transformation processes taking place in the changing world that is becoming post-biospheric. Interdisciplinary philosophical view allows capturing the world in the integrity of its diverse characteristics and at the same time forming a problem field for visualizing transformational processes. The fundamental role of the integration link belongs to information technology, which allows us to represent visually heterogeneous data with the aim of further developing models for the safe development of mankind in the technosphere.
\end{abstract}

Keywords: socio-techno-natural globalization, social-technogenic development, technosphere, biosphere, visual model, regularities.

\section{Introduction}

Visualization is a powerful tool for pictorial presentation of the transformation processes taking place in the world. Detailed information about changes in social, technical, and naturalbiological systems become most acute when it is visually reproduced, which makes it possible to convey fundamental and applied research data to potential audiences as fast and as efficiently (compared to textual reproduction), to introduce to the interested audience scientists' thoughts and discoveries. This applies to social and humanitarian, as well as natural, and technical sciences. Information visualization is mainly the territory for presenting applied research data, which, unlike the fundamental ones, accounts for up to $90 \%$ of all scientific work carried out in the world. A wide range of visual interpretation of data on heterogeneous socio-economic, technical, technological and environmental changes is the core of visual analysis and modeling of global and local processes. Moreover, visualization is not just a means of displaying indicators, but is a complete tool of identifying trends and prospects for the phenomena development. Visualization tools contribute to activating the thinking processes of scientists of different scientific specializations, direct them into the mainstream of new research issues. Thus, visualization helps to develop interdisciplinary research themes and cooperation.

At the beginning of the $\mathrm{XXI}^{\mathrm{st}}$ century philosophy as an area of interdisciplinary research is increasingly involved in understanding the relationship between mankind and the technosphere, created by people on the basis of scientific and technological progress, and at that the mass of the new, artificial shell of the planet approaches the size of the remnants of living matter of the biosphere. Now the planet is dominated by interconnected social and technological transformation processes that lead to changes both in the social structure of the world and are accompanied by the biosphere degradation. Such a comprehensive expansion of the artificial intervention created by mankind is accompanied by a complex integration of the processes of social, technospheric and natural biological evolution, which is reflected in the processes of systemic social and natural globalization [10]. The growing technogenicity of the processes and problems that make up the modern globalization leads to a change in the centuries-old biological evolution of life in the biosphere to an artificial, post-biosphere one that is evolution of life without a biosphere as a self-developing system [5]. The philosophy of socio-technogenic development of the world and integrated socio-techno-natural processes allows us to analyze the changing nature of biological evolution and the scientific picture of the world as a whole [4].

Nevertheless, visual modeling and its tools are still far from presenting integrative models of socio-techno-natural processes, i.e. presenting evolutionary changes simultaneously in three systems - society (and man), the technosphere and the technologically transformed biosphere. A broad sociophilosophical view allows us to embrace the world in the integrity of its diverse characteristics and at the same time to form a problem field for visualizing transformational processes. This largely transdisciplinary approach challenges the field of information technology by the visual representation of the transitional processes of social and technological nature occurring in the world. Visualizing these phenomena, which are the stratum of modern systemic globalization, is extremely necessary with the aim of their subsequent interdisciplinary understanding and revealing hidden regularities.

It is enough to pay attention to the vector of the artificial direction of life, which has been growing rapidly over the last third of the century, when, against the background of a $75 \%$ decrease in the number of flying insects in the world and the loss of half the number of birds, a tremendous three-fold increase in the mass of the artificial urban environment is recorded [20]. 4.2 billion people live in this environment at the end of the second decade of the $\mathrm{XXI}^{\text {st }}$ century and this figure is more than half of the world population.

The difficulties of such a task of visualizing the most complex development processes are concluded in the need to intensify interdisciplinary research based on philosophy as integrative knowledge with the inclusion of information technology tools.

\section{Methodology}

The success of any research work on visualizing a large amount of data with a complex structure depends on the right tools, which can reduce the information load on a person, focus the attention on really important interrelations, identify unambiguous conclusions and even make predictions for the 
future. Naturally, here we are talking about well-known graphical visualization methods which are linear methods, histograms, pie charts, maps, trees that display relations, data distribution, their composition in socio-economic, technological and natural-biological systems for the purpose of their subsequent comparison. The visualization methodology is described in detail in the works C. Chen, D. Huang, M. Tory, Ed. Tufte, A.E. Bondareva, V.A. Galaktionova, A.A. Zakharova et al. $[2,3,13,18]$. In their works, special attention is paid to the interpretation of images presented during computer modeling, which is of undoubted importance for analyzing and forecasting integrative socio-techno-natural processes.

Nevertheless, the information technology toolkit captures the connections and reflects the dependencies "delivered" by the "Big" science. Specialization of the latter is extremely heterogeneous in the vast world and domestic thought. This, in particular, according to the data presented by the Centre for Strategic Planning of the Russian Academy of Sciences, is indicated by the scientific specialization index calculated for countries of the world based on publications in the WOS and Scopus databases (2016). So, Russia is characterized by the highest degree of narrowly disciplinary specialization of scientific research in the natural sciences, humanities and technical sciences (in particular, physics, chemistry, earth sciences), which is characteristic of the state of science of the world countries of the $80 \mathrm{~s}$ of the last century, i.e. forty years ago (Fig. 1).
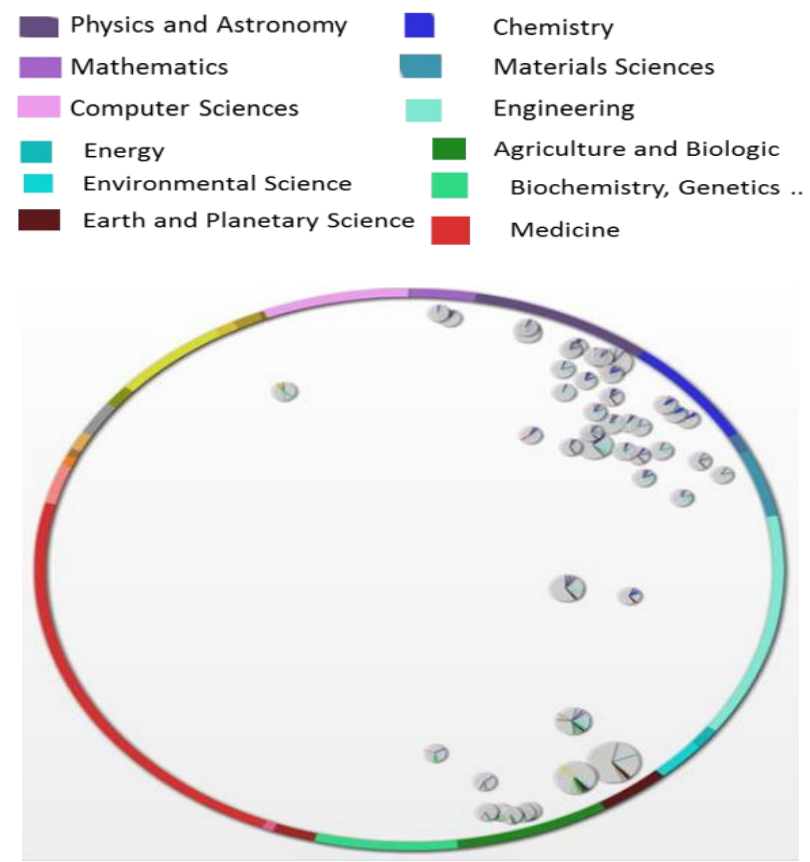

Fig. 1. Russia: distribution by the themes of priority research (according to the data of the Central Statistical Bureau of the Russian Academy of Sciences, 2016)

The "flagships" of the modern world - the USA, a number of countries in Western Europe, Japan and China have the most developed interdisciplinary relations for the science. It is important to note basing on the analysis of publications that interdisciplinary scientific activity in the United States is evenly distributed across all scientific areas, while the highest degree of attention is focused on the human sciences, the human health, and medical technologies (Fig. 2). In China, there is a slightly different picture and publications in the field of chemistry, energy and ecology have an advantage.

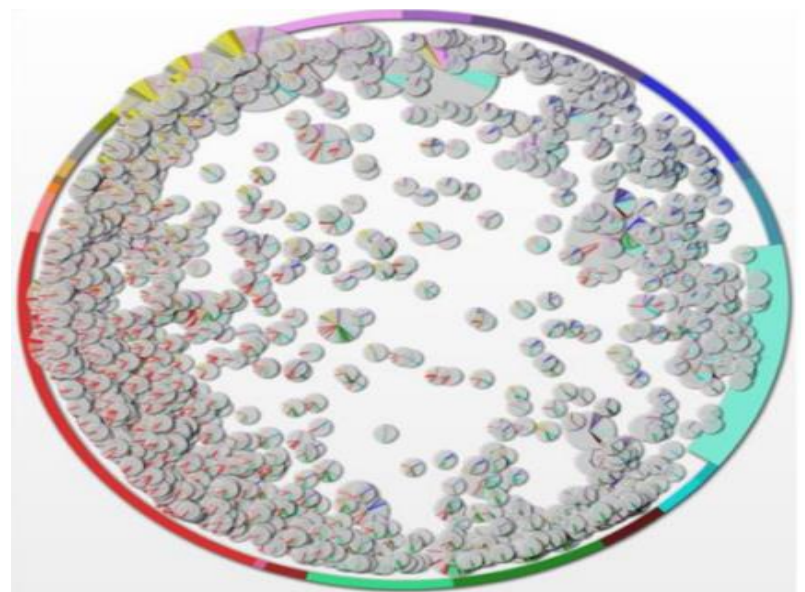

Fig. 2. USA: distribution by themes of priority research (according to the data of the Central Statistical Bureau of the Russian Academy of Sciences, 2016)

In general, the most priority areas of science for the developed countries of the world in 2010-2020 are researches in nano-, bio-, information, cognitive technologies, supported by the potential of the social sciences and humanities, and such sciences as environmental engineering, applied physics and environmental biotechnology are becoming the main focus of attention. This integration of sciences and technologies is called the NBIC (C)-convergence (according to the methodology of M. Roco \& W. Bainbridge [17], M.V. Kovalchuk [15]) and puts on the agenda the question of the need for a convergent nature of education [1] in the context of its highly specialized orientation, leaving aside the general picture of the world changes [14]. But all these integrative relations are inconceivable without their comprehensive transdisciplinary understanding, which is also realized through philosophy. The latter combines scientific and extra-scientific knowledge, the social experience of mankind, hypotheses, sociocultural values, prognostic ideas, which subsequently "descend" through the floors of narrowly disciplinary science, finding their confirmation.

Until the beginning of the $19^{\text {th }}$ century the way of life of the agrarian society was associated with living in agricultural settlements and manual work, while more than two-thirds of all activities were based on attracting the muscular energy of domestic animals. But the powerful rise of industrial-urban development radically changed priorities in the alignment of productive forces in the world economy. Now, up to $99 \%$ of the work performed by society is connected with technical energy, while two centuries ago, the same amount of work was performed by human and animals [6]. For almost ten thousand years of agricultural history, the economic society significantly changed the surrounding natural world, which was accompanied by the biosphere cultivation, local environmental crises and the gradual rise of civilizational development. However, over the last two or three centuries of industrial and technological development, the natural world has changed much more in its hydrospheric, atmospheric, and especially lithospheric shells than in the previous centuries of agrarian management, which was partially reflected in visualization models.

Among the visualizations of 2018 that most clearly reflect the anthropogenic impact on natural-biological systems, we note the plastics pollution of the world oceans, presented in the interactive pictures of the "National Geographic publication"; infographics of the "Guardian publication" of seven endangered species of animals, the number of which occupies only a train carriage; earlier dates of spring coming on the planet and the appearance of the first leaves on trees compared with the data of fifty years ago, which is a consequence of climate changes et al. This information is presented in Washingtonpost (Fig. 3). These 
visualizations make people think about the apocalyptic nature of technogenic transformations, understand the acuteness of the tragedy occurring on the Earth. At the same time, in these nature visualizations, the analysis of developing life is built without taking into account the systemic technological changes in the world.

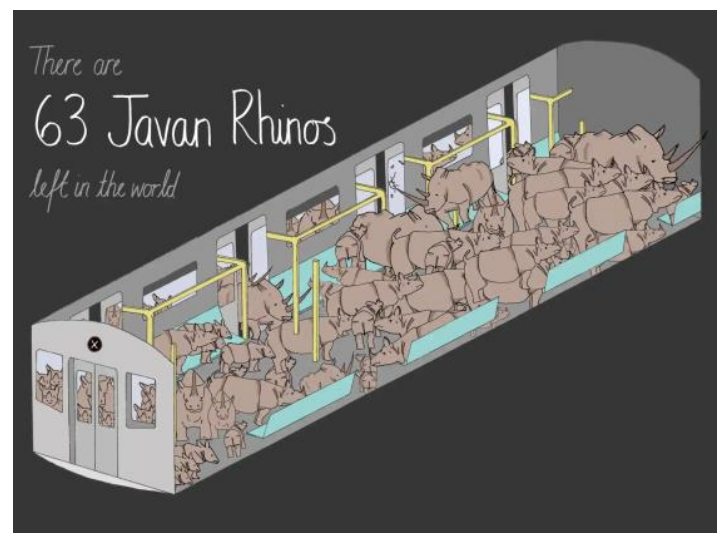

Fig. 3. Infographics showing the number of Javanese rhinos remaining on the planet (The Guardian, Environment gallery, 09.17.2018)

Now the planet is a developing technosphere, it is an expanding network of urban settlements mainly made from artificial materials, tools and objects, synthesized substances and technological electromagnetic radiation. Living in such an environment is associated with the lifestyle and socialization processes of the majority of the world population [10].

Many of these and other technocratic factors of changing the world on the basis of machine technology demanded transferring the philosophical thought to new understanding of ongoing global processes based on the advanced achievements of the scientific thought. Along with the directions of the biosphere and noosphere philosophy that appeared in the $20^{\text {th }}$ century, scientific and technological progress, post-industrial (and information) society, at the turn of the century there arises a new multidisciplinary scientific and philosophical direction of research that is the research of social and technological development of the world, social and natural processes and changes in the evolution of life. Bryansk State Technical University has formed a scientific school led by Professor E.S. Demidenko, which prepares specialists in various fields to reflect on the new frontiers of the interconnected development of the society and nature. Among the areas being actively developed by the school are new patterns of socio-technogenic development, creating new paradigms in the philosophy of the technosphere, changes in the evolution of life, socio-techno-natural globalization, a technocratic market economy, etc. [8].

The philosophy of socio-technogenic development of the world builds its arguments on the methodology of a systemic socio-natural approach based on the ideas of V.I. Vernadsky about the noosphere and the changing historical parameters of the society and the biosphere during their interaction. At the beginning of $\mathrm{XX}^{\text {th }}$ century V.I. Vernadsky was one of the first who paid attention to the interconnected development of social and natural processes, optimistically considered that the society was creating a new world - the noosphere in the form of an improved biosphere based on the collective mind, science and labor of associated humanity [19]. At the beginning of the XXI ${ }^{\text {st }}$ century the social-natural approach finds development in the works of E.S. Demidenko and followers of the theory of the world social and technogenic development, philosophers and scientists of the leading universities of the country and abroad [4, $9,16]$. Now we can state that the noosphere is formed in the guise of a technosphere that guides the world along the steps of the social and natural evolution of life [6].

All these and many other facts of the changing dynamics of the joint evolution of society, the technosphere and biosphere, indicate that the universally recognized visualization methodology needs to be supplemented with the methodology of social and technogenic development of the world and life for a better visual representation and explanation of the transformation processes taking place in the world, of a changing picture of the world, becoming a post-biosphere one [7]. This will allow seeing the prospects and threats of developing life on the Earth on a large scale of global socio-techno-natural trends $[5,10]$.

Thus, with the help of visualization models, the reader is given an opportunity to consciously realize the catastrophic technological processes occurring in the world. Infographic warns the reader, makes him or her involved in the possibility of making the contribution to the common cause of preserving the biosphere as the only yet possible area of maintaining vital activity on the planet. And this task is all the more important, as through vision a person perceives up to most of information, subsequently processing it into knowledge. How realizable is the task of developing an interdisciplinary visualization methodology is a question and a problem of the near future. But one thing is clear - this is a challenge not only to information technology, but to the whole range of related sciences aimed at achieving the goals of sustainable social and natural development.

\section{Results and discussions}

The UN Conferences on Environment and Development of 1992 and 2012 were the largest milestones in the history of discussing the problems of achieving the sustainability of coevolutionary development of the society and nature, preserving the biosphere for future generations. Documents proposed at the conferences are widely reflected in visualization models. However, the theory of sustainable development in all the variety of research approaches has remained only a good wish so far, since for a third of a century of its existence, the world has taken the extremely dangerous path of social and technogenic development of life.

The imperfection of theories of sustainable development is due to fragmentation of research issues, based on the two main concepts of globalization entrenched in international global studies - economic and socio-ecological (socio-natural) concepts in a variety of author's points of view [11, 12]. In these theories, the emphasis is on the social conditioning of globalization processes, while biological regularities, as advocates of socioeconomic theories believe, are studied by purely natural sciences.

If we are guided by the methodology of data analysis tasks using analytical visual models [18] and analyze only social (and economic) systems and processes, then the set of intermediate states of such models, taking into account leading corrective questions, hypotheses, and data verification results, will ultimately help us to make up the final visual image of the model, considering only the social laws of its development. Therefore, visualization models that consider in isolation socio-economic, technical, technological and natural-biological laws of development give a one-sided view of global processes and problems, which undoubtedly limit the possibilities of carrying out sustainable development and forecasting programs.

At the same time, in modern conditions, when the technosphere becomes an active intermediary between a globalizing society and transforming nature, we should talk about integrative socio-natural models of data visualization, which allow us to identify and analyze complex, integrated laws of the world social and natural development and the evolution of life. The facets of technogenicity of the socio-natural evolution of life, its transition to post-biosphere, semi-artificial life forms - 
transgenic, cloned, biotechnological, the replacement of natural biogeochemical metabolic processes with artificial cycles of substances, the global technogenic transformation of the human being as a biosocial organism are not comprehensively reflected in the documents of sustainable development, integral indicators and data visualization models.

At the beginning of the $\mathrm{XXI}^{\text {st }}$ century, with the development of convergent nano-, bio-, informational, cognitive and social (i.e. NBIKS) technologies, a technogenic society is actively transforming natural biological systems. The main developers of such technologies are transnational corporations that produce genetically modified living organisms on a commercial basis and distribute them. Global business players are deliberately expanding technogenicity in the forms of creating biological life, involving in the market economy and reproduction of the technosphere other agrarian societies which are in technical and technological dependence on the world developed countries. Thus, there is a globalization of the industrial-technogenic model of development, and with it a qualitative change in the natural environment.

The new socio-philosophical interdisciplinary concept of the socio-technological globalization developed and substantiated by the author allows us to consider in a unity the interconnected changes in the society (and its economy), the biosphere and man in the context of the transition of life into a technospheric-urban environment. Such understanding of planetary changes provides opportunities for the active study of modern socio-technogenic transformational processes in the complex by all sciences - social, technical, and natural. More generally, an interdisciplinary approach to global and local processes will make it possible to plan programs for the safe socio-economic and socio-techno-natural development of the world and Russia [10].

The all-round expansion of artificial things made by mankind, as shown in the studies of Professor E.S. Demidenko and the author of the article, leads to a change in the centuriesold biological evolution of life in the biosphere to the postbiosphere one - without the biosphere as a self-developing system. Among the main global "markers" of the change in the direction of the evolution of life on the Earth, it is necessary to note the most significant marker for its predictive development this is the destruction and even death of the biosphere as a global life system in which humanity developed [5]. The biosphere is deprived of the woven variety of living matter that has developed over 4 billion years: plants, animals, microorganisms, soil cover. It is evidenced by the loss of more than two-thirds of the world forests, the facts of going into oblivion over half of living organisms in the $\mathrm{XX}-\mathrm{XXI}^{\text {st }}$ centuries, as confirmed by the infographics of the living planet index (Fig. 4).

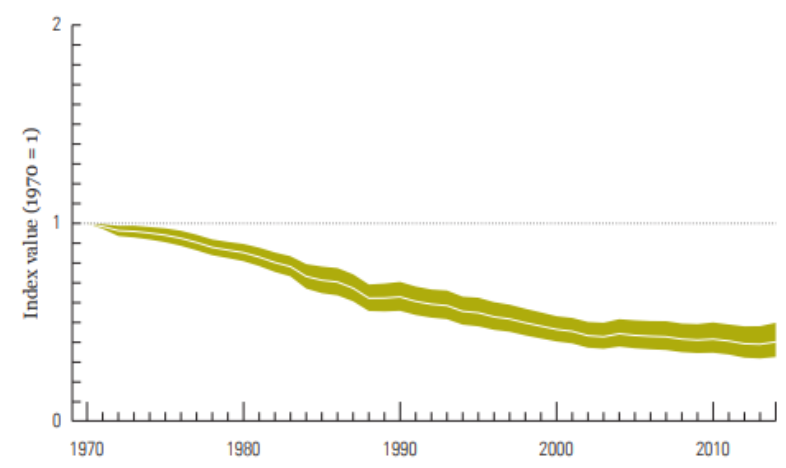

Fig. 4. Global Living planet index from 1970 to 2014 (according to the data of WWF.Living Planet Report - 2018).

The average number of 16,704 populations, 405 species monitored worldwide was reduced by $60 \%$. The white line shows the index value, and the shaded areas are the statistical significance of the trend (from 50 to 67\%) [20]
Natural biological life, undergoing significant technogenic transformations, passes into the artificial urban conditions of its development, in which at the beginning of the current century about half of the biomass of terrestrial animals and about a third of plant species cultivated by the society live. For Russia, a relatively optimistic scenario of industrial and technological development is still preserved, since there are significantly more than half of the biosphere resources on its territory, while the USA has $5 \%$ of biosphere forests and soils in agriculture [5].

More than 150 thousand new toxic chemicals enter the biosphere annually; the effect of most of them on the animals, plants, and humans has not been studied at all [4]. All these technological innovations adversely affect the person himself, which, along with other diseases, has led to the growth of the disease "cancer" by three times in the last two decades of the new century [5]. And here we are already dealing with the sociotechno-natural laws of changing the biology of the modern world, which requires immediate visual reflection in order to consciously approach models of market utilitarian-pragmatic progress, to search for new patterns and ways to prevent apocalyptic development scenarios. The laws of changing the social world are still subject to the financial interests of business owners who exploit the wealth of nature. Therefore, the propaganda of the social and environmental responsibility of technocratic political and economic elites only veils the selfish interests of business.

Among the brightest global socio-techno-natural processes of our time, requiring the immediate development of visual models, an oil spill in the Gulf of Mexico in 2010, caused by the activities of the American oil corporation, should be given as an example. However, such a man-made accident led to a cooling of the warm North Atlantic Gulf Stream and a decrease by one third of its capacity [21], which turned into a sudden cooling in the winter period in Western Europe in 2011-2012. In order to conceal the size of the crime, a new life form created on the basis of information technology was released into the bay called the artificial bacterium Cynthia, which is capable of selfreproduction. After the absorption of petroleum organics, the cell began to penetrate into the bodies of marine fauna, as well as people swimming in the bay, which led to ulcerations on the skin and diseases of the internal organs that were difficult to treat [10]. The ways of spreading new artificial life in the ocean are poorly studied, but cases of its presence in the Mediterranean and Black Seas have already been recorded. Visual modeling of the sociotechno-natural processes will allow us to analyze both the goals and the conflicting consequences of technogenic transformations.

\section{Conclusion}

The issue of choosing a safe development of life, implemented on the basis of constructing conceptual and strategic models of visualization, should not be discounted from a technologically developing society. To overcome negative technocratic trends, it is necessary to use all the tools of information technology, conduct interdisciplinary fundamental research by the institutes of the Russian Academy of Sciences with the support of the State Duma and the Government of Russia with the involvement of regional science communities. On the basis of such scientific integration and construction of visual models, proposals for the UN will be carried out with the aim of solving the problem of sustainable development of the society and the biosphere.

\section{Acknowledgments}

I express gratitude to the professor Doctor of Philosophy E.S. Demidenko, head of the Interdisciplinary Scientific and Philosophical School of Research on the Social and Technogenic Development of the World, Socio-techno-natural Processes and 
Changing the Evolution of Life, to my scientific adviser, for the cooperation and help in choosing the direction of scientific research.

\section{References}

[1] Backsanskij, O.E., Dergacheva, E.A.: The Formation of a New Paradigm in Education: From Convergent Technologies to Understanding Social and Technogenic Transformations in the World. Smart Technologies and Innovations in Design for Control of Technological Processes and Objects: Economy and Production, (139), pp.136-142 (2019). Available at: https://link.springer.com/chapter/10.1007/978-3-03018553-4_18, https://doi.org/10.1007/978-3-030-185534_18.

[2] Bondarev A.E., Galaktionov V.A.: Multidimensional data analysis and visualization for time-dependent CFD problems. Programming and Computer Software 41(5), 247-252 (2015). DOI: 10.1134/S0361768815050023

[3] Chen, C.: Mapping Scientific Frontiers: The Quest for Knowledge Visualization. 2nd ed. London, Springer (2013).

[4] Demidenko, E.S., Dergacheva, E.A., Popkova, N.V.: The philosophy of the world social and technogenic development: articles, concepts, terms. Moscow, Bryansk, The World inform-encyclopedia, BSTU publishing House (2011).

[5] Demidenko, E.S., Dergacheva, E.A.: From the global degradation of the biosphere to the change of life evolution: a scientific report. Moscow, Publishing House of the Russian Academy of Sciences (2017).

[6] Demidenko, E.S., Dergacheva, E.A.: Technogenic development of society and transformation of biosphere. Krasand, Moscow (2010).

[7] Demidenko, E.S.: Understanding the transformation of the biosphere picture of the world in the conditions of sociotechnogenic development of life on the Earth. Economics in the conditions of socio-technogenic development of the world: proceedings of the International Conference on Fundamental and Applied Problems of Economic and Environmental Development, Bryansk State Technical University, Russian Academy of Sciences, (1), pp.5-16 (2016).

[8] Dergachev, K.V., Trifankov, Yu.T.: Modern Philosophy in the Context of Interdisciplinary Studies of Human and Nature. Smart Technologies and Innovations in Design for Control of Technological Processes and Objects: Economy and Production, (139), pp.228-233 (2019). Available at: https://link.springer.com/chapter/10.1007/978-3-03018553-4_29

[9] Dergachev, K.V.: Man and his prospects under conditions of virtual reality development. The European Proceedings of Social \& Behavioural Sciences. International Conference «Responsible Research and Innovation», pp. 209-216 (2017). Available at: http://dx.doi.org/10.15405/epsbs.2017.07.02.27

[10] Dergacheva, E.A.: Concept of socio-techno-natural globalization: Interdisciplinary analysis. Moscow, Lenand, URSS (2016).

[11] Encyclopedia of Globalization. In: Scholte, J.A., Robertson, R. (ed.). Routledge, N.Y., London (2006).

[12] Global studies: International Interdisciplinary Encyclopedic Dictionary. In: Mazur, I.I., Chumakov, A.N. (eds.). Moscow, Saint Petersburg, New York (2006).

[13] Huang, D., Tory, M., Adriel Aseniero, B., Bartram, L., Bateman, S., Carpendale, S., Tang, A., Woodbury, R.: Personal visualization and personal visual analytics. IEEE Trans. Vis. Comput. Graph. 21, 420-433 (2015).
[14] Kolesnik, T.A.: Technocratic nature of education in the market. Economy in the conditions of social and technogenic development of the world: proceedings of the 2nd International Interdisciplinary Scientific Conference on Fundamental and Applied Problems of Modern Socioeconomic and Economic-ecological development, Bryansk State Technical University, Russian Academy of Sciences, (1), pp.118-125 (2017).

[15] Kovalchuk, M.V.: Science and life: my convergence. Moscow, Akademkniga (2012).

[16] Philosophy of social interaction in the age of convergent technologies: collect. monograph. Liseev, I.K. (Ed.) (Institute of Philosophy of RAS). Moscow, St. Petersburg, Nestor-History (2018).

[17] Roco, M., Bainbridge, W.: Converging Technologies for Improving Human Performance: Nanotechnology, Biotechnology, Information Technology and Cognitive Science. Arlington (2004)

[18] Shklyar, A.V., Zakharova, A.A., Vekhter, E.V.: Methodology for solving data analysis problems using analytical visual models. Scientific Visualization, 4(9), pp.78-88 (2017). Available at: http://sv-journal.org/20174/08/index.php?lang=ru

[19] Vernadsky, V.I.: Biosphere. Noosfera, Moscow (2001).

[20] WWF. Living Planet Report - 2018: Aiming Higher. Grooten, M. and Almond, R.E.A.(Eds). WWF, Gland, Switzerland (2018).

[21] Zangari, G. Risk of Global Climate Change by BP Oil Spill. Available at: http://www.associazionegeofisica.it/OilSpill.pdf 